\title{
Produtividade de arroz de terras altas em função de reguladores de crescimento
}

\author{
Rita de Cassia Felix Alvarez, Carlos Alexandre Costa Crusciol ${ }^{2}$, Adriano Stephan Nascente
}

\begin{abstract}
RESUMO
O uso de irrigação por aspersão e, ou, de níveis elevados de adubação, no arroz de terras altas, pode resultar no aumento da altura de plantas e, consequentemente, em maiores taxas de acamamento. Para resolver esse problema, podem-se utilizar reguladores vegetais, como forma de reduzir a altura da planta. Objetivou-se, com este trabalho, avaliar a eficiência de reguladores vegetais, aplicados no estádio de diferenciação do primórdio da panícula, na redução da altura da planta, e suas consequências nos componentes da produção e da produtividade de grãos do arroz de terras altas, cv. Primavera, irrigado por aspersão. O delineamento experimental foi em blocos casualizados, dispostos em esquema fatorial $3 \times 4$, com quatro repetições. Os tratamentos foram: cloreto de mepiquat e etil-trinexapac, aplicados nas doses $0,50,100 \mathrm{e} 200 \mathrm{mg}$ i.a. ha ${ }^{-1}$, e, o paclobutrazol, nas doses $0,25,50 \mathrm{e} 100 \mathrm{mg}$ i.a. ha ${ }^{-1}$. Os reguladores vegetais reduzem a altura da planta e o aumento das doses dos reguladores reduziu os valores dos componentes da produção e da produtividade de grãos; o etil-trinexapac foi o regulador mais prejudicial à produtividade do arroz; não foi identificada uma dose adequada de regulador que aliasse à redução da altura das plantas a capacidade de aumentar a produtividade de grãos.
\end{abstract}

Palavras-chave: Oryza sativa L., acamamento, cloreto de mepiquat, etil-trinexapac, paclobutrazol.

\begin{abstract}
\section{Upland rice yield as a function of growth regulators}

The use of sprinkler-irrigation and/or high levels of fertilization in upland rice can increase plant height and hence plant lodging. Lodging can be controlled by using growth regulators, in order to reduce plant height. The objective of this study was to evaluate the efficiency of plant growth regulators applied at the stage of panicle primordium differentiation on the reduction of plant height and the impact on grain yield and its components of upland rice cultivar Primavera, under sprinkler irrigation. The experiment was arranged in a $3 \times 4$ factorial randomized blocks design with four replications. Treatments consisted of: mepiquat chloride and trinexapac-ethil applied at doses 9, 50, 100, and $200 \mathrm{mg}$ a.i. ha-1, and paclobutrazol at doses of 0,25,50, and $100 \mathrm{mg}$ a.i. ha-1. Plant growth regulators reduced rice plant height; increasing doses of regulators reduced upland rice grain yield and its components; trinexapac-ethyl was the most harmful to rice grain yield.In this study, it was not identified the dose of growth regulator that allied reduction in plant height and did not cause decrease in rice yield.
\end{abstract}

Key words: Oryza sativa L., lodging, mepiquat chloride, ethyl-trinexapc, paclobutrazol.

Recebido para publicação em 12/09/2012 e aprovado em 04/07/2013.

${ }^{1}$ Engenheira-Agrônoma, Doutora. Departamento de Agronomia, Universidade Federal do Mato Grosso do Sul, Caixa Postal 112, 79560-000, Chapadão do Sul, Mato Grosso do Sul, Brasil.rita.alvarez@ufms.br

2Engenheiro-Agrônomo, Doutor. Departamento de Produção Vegetal (Agricultura), Universidade Estadual Paulista, Caixa Postal 237, 18603-970, Botucatu, São Paulo, Brasil. crusciol@fca.unesp.br

${ }^{3}$ Engenheiro-Agrônomo, Doutor. Embrapa Arroz e Feijão, Rodovia GO-462, Km 12, Zona Rural, Caixa Postal 179, 75375-000, Santo Antônio de Goiás, Goiás, Brasil. adriano.nascente@embrapa.br (autor para correspondência). 


\section{INTRODUÇÃO}

O cultivo de arroz de terras altas, apesar de ocupar $65 \%$ da área total cultivada com arroz, no Brasil, contribui com apenas $41 \%$ da produção nacional (CONAB, 2011). A principal razão dessa baixa produtividade, no ambiente terras altas, é atribuída à má distribuição pluvial nas regiões produtoras e ao baixo uso de adubos e corretivos (Alvarez et al., 2007; Bosco et al., 2009). Nesse sentido, o sistema irrigado por aspersão confere estabilidade à produção, aumenta a produtividade e favorece a melhoria da qualidade de grãos (Crusciol et al., 2012).

No entanto, um dos grandes problemas do arroz de terras altas, quando se utilizam cultivares do tipo tradicional, ou do tipo intermediário, e se empregam doses elevadas de adubação, notadamente a nitrogenada, acompanhadas por práticas como a irrigação por aspersão, é o aumento da altura e, consequentemente, o acamamento de plantas (Soares et al., 2003; Nascimento et al., 2009; Fageria et al., 2011; Crusciol et al., 2012).

Como alternativa para diminuir a altura das plantas de arroz, e, com isso, também o acamamento, tem-se a utilização de reguladores vegetais (Buzetti et al., 2006; Campos et al., 2009). Os reguladores vegetais, neste caso, retardantes vegetais, são compostos sintéticos utilizados para reduzir o crescimento em altura, indesejável, da parte aérea das plantas, sem diminuição da produtividade (Rademacher, 2000; Alvarez et al., 2007, 2012).

Os reguladores vegetais foram desenvolvidos como agentes antiacamamento para cereais e gramíneas, e como inibidores de crescimento para gramados (Fialho et al., 2009; Alvarez et al., 2012). No Brasil, esses produtos são utilizados como maturadores de cana-de-açúcar e promovem aumento de rendimento de açúcar, sem impacto negativo na qualidade do caldo, no conteúdo de fibras ou na massa de colmos (Viana et al., 2008). Têm sido utilizados com sucesso na cultura do trigo, visando à redução da altura de plantas, evitando o acamamento (Zagonel \& Fernandes, 2007; Espíndula et al., 2011). Para a cultura do arroz de terras altas, ainda existem poucas informações sobre a aplicação de biorreguladores, visando a reduzir a altura das plantas e seus efeitos nos componentes de produção e produtividade da cultura (Buzetti et al., 2006; Alvarez et al., 2007; Nascimento et al., 2009).

Este trabalho visa a testar a hipótese de que a aplicação do regulador vegetal, com diferentes princípios ativos, na dose adequada, poderá propiciar a redução da altura de plantas, sem afetar negativamente os componentes de produção e a produtividade de grãos do arroz de terras altas, irrigado por aspersão. Assim, o objetivo deste trabalho foi de avaliar a eficiência de reguladores vegetais, aplicados no estádio de diferenciação do primórdio da panícula, na redução da altura da planta, e suas consequências nos componentes de produção e na produtividade de grãos do arroz de terras altas, cv. Primavera, irrigado por aspersão.

\section{MATERIAL E MÉTODOS}

O experimento foi realizado na Fazenda Experimental Lageado, pertencente à Faculdade de Ciências Agronômicas da UNESP, município de Botucatu, SP (48 23' W, $22^{\circ} 51^{\prime} \mathrm{S}$ e $765 \mathrm{~m}$ de altitude), em solo classificado como NITOSSOLO VERMELHO Distroférrico (Embrapa, 1999), O clima da região, segundo a classificação de Köppen, é do tipo Cwa, temperado quente (mesotérmico), com inverno seco e verão quente e chuvoso, com temperatura média anual, no ano do experimento, máxima de $26,5^{\circ} \mathrm{C}$, mínima de $17^{\circ} \mathrm{C}$ e precipitação anual de $1455 \mathrm{~mm}$.

Os atributos químicos do solo, antes da instalação do experimento, na camada de 0 a $0,20 \mathrm{~m}$, foram: $\mathrm{pH}\left(\mathrm{CaCl}_{2}\right)$ 5,0; $21 \mathrm{~g} \mathrm{~kg}^{-1}$ de M.O.; 35,4 mg dm${ }^{-3}$ de P (resina); 2,5; 38; 17,4 e 43 mmol $_{c} \mathrm{dm}^{-3} \mathrm{de} \mathrm{K}, \mathrm{Ca}, \mathrm{Mg} \mathrm{e} \mathrm{H}+\mathrm{Al}$, respectivamente, e $57 \%$ de saturação por bases, segundo método proposto por Raij et al. (1996), bem como 240, 110 e $650 \mathrm{~g} \mathrm{~kg}^{-1}$ de areia, silte e argila, respectivamente.

O delineamento experimental foi em blocos casualizados, dispostos em esquema fatorial $3 \times 4$, com quatro repetições. Cada unidade experimental continha seis fileiras de plantas, com oito metros de comprimento. Os tratamentos foram constituídos de três reguladores vegetais e quatro doses. O cloreto de mepiquat (PIX) e o etiltrinexapac (Moddus) foram aplicados nas doses de 0, 50, $100 \mathrm{e} 200 \mathrm{~g}$ do ingrediente ativo (i.a.) ha ${ }^{-1} \mathrm{e}$, o paclobutrazol (Paclobutrazol ou Cultar), nas doses de 0, 25, 50 e $100 \mathrm{~g}$ i.a. ha ${ }^{-1}$. Essas doses corresponderam a zero, metade da dose, dose recomendada e dobro da dose recomendada pelo fabricante. Os reguladores vegetais foram aplicados no estádio de diferenciação do primórdio da panícula, na forma de jato dirigido, com pulverizador manual tipo costal, com pressão constante de $\mathrm{CO}_{2}$, utilizando-se bico cônico tipo TX-VS2, com volume de calda aproximado de $100 \mathrm{~L}$ $\mathrm{ha}^{-1}$. As soluções dos reguladores foram preparadas com surfatante não iônico $\left(0,05 \%\right.$ - $\left.50 \mathrm{~mL} 100 \mathrm{~L}^{-1}\right)+$ ureia $(1,0$ $\%$ ), para melhor adesão e absorção.

O preparo do solo foi realizado por meio de uma aração e duas gradagens. Realizou-se a adubação química básica nos sulcos de semeadura, com $20 \mathrm{~kg} \mathrm{ha}^{-1} \mathrm{de} \mathrm{N}$, na forma de ureia, $30 \mathrm{~kg} \mathrm{ha}^{-1}$ de $\mathrm{P}_{2} \mathrm{O}_{5}$, na forma de superfosfato simples e $30 \mathrm{~kg} \mathrm{ha}^{-1}$ de $\mathrm{K}_{2} \mathrm{O}$, na forma de cloreto de potássio. Na adubação de cobertura, foram utilizados $90 \mathrm{~kg}$ de $\mathrm{N} \mathrm{ha}^{-1}$, na forma de ureia, parcelada em duas vezes, aos 30 dias após a emergência (DAE), no estádio de perfilhamento, e aos 63 DAE, no estádio de diferenciação do primórdio da panícula, com $45 \mathrm{~kg}$ de $\mathrm{N} \mathrm{ha}^{-1}$, cada (Raij et al. 1996). A semeadura foi realizada em dezembro, utilizan- 
do-se a densidade de 200 sementes viáveis $\mathrm{m}^{-2}$, no espaçamento de 0,40 m entrelinhas e densidade de semeadura de 80 sementes por metro. Foi utilizado o cultivar Primavera (Soares et al., 2001) e os tratos culturais foram realizados de acordo com as necessidades da cultura.

A área foi irrigada com sistema fixo de irrigação convencional por aspersão, com vazão de $3,3 \mathrm{~mm} \mathrm{~h}^{-1}$ nos aspersores. No manejo de água, foram utilizados três coeficientes de cultura $(\mathrm{Kc})$, distribuídos em quatro períodos, compreendidos entre a emergência e a colheita. Para a fase vegetativa, foi utilizado o valor de 0,4 ; para a fase reprodutiva foram dois valores de Kc, o inicial de 0,7 e o final de 1,0 e, para a fase de maturação, esses valores foram invertidos, ou seja, o inicial de 1,0 e o final de 0,7 conforme sugerido por Rodrigues et al. (2004).

As avaliações realizadas foram da altura da planta: da distância média (cm), compreendida desde a superfície do solo até a extremidade superior da panícula mais alta, determinada em dez plantas, ao acaso, na área útil de cada parcela; do número de panículas por metro quadrado: do número de panículas contidas em 1,0 m de fileiras de plantas, na área útil das parcelas, posteriormente convertido para número de panículas $\mathrm{m}^{-2}$; do número total de espiguetas por panícula: do número de espiguetas de 20 panículas por unidade experimental, coletadas ao acaso, no momento da avaliação do número de panículas por metro quadrado; da fertilidade das espiguetas, determinada para cada unidade experimental a partir da relação: número de espiguetas granadas por panícula, pelo número total de espiguetas por panícula, multiplicado por 100; da massa de 1000 grãos, determinada por pesagem de quatro amostras, coletadas ao acaso, de 1000 grãos de cada parcela (130 $\mathrm{g} \mathrm{kg}^{-1}$ base úmida). A colheita do arroz foi efetuada manualmente, na maturação fisiológica da cultura. A seguir, foram realizadas a trilha manual, a secagem à sombra e a limpeza do material, e determinou-se a massa dos grãos colhidos, calculando-se a produtividade de grãos por hectare ( $\mathrm{kg} \mathrm{ha}^{-1}-130 \mathrm{~g} \mathrm{~kg}^{-1}$ base úmida).

Os resultados foram submetidos à análise de variância. As médias referentes aos reguladores vegetais foram comparadas pelo teste de Tukey para $\mathrm{p}<0,05$, enquanto os efeitos das doses foram avaliados por meio de análise de regressão, adotando-se como critério para escolha do modelo matemático a magnitude dos coeficientes de regressão significativos, a 5\%, pelo teste t.

\section{RESULTADOS E DISCUSSÃO}

A altura da planta foi influenciada significativamente pelos tratamentos (Tabela 1) e pela interação fonte e dose (Figura 1). Dessa forma, verificou-se redução linear significativa da altura das plantas, com o aumento das doses dos reguladores vegetais, sendo mais acentuada com a aplica- ção do etil-trinexapac (ETX) (Tabela 2). Esses resultados corroboram os obtidos por Rademacher, (2000), Alvarez et al. (2007), Nascimento et al. (2009) e Alvarez et al. (2012), em cujos trabalhos a aplicação de reguladores também afetou significativamente a altura de plantas de arroz.

O efeito de redução da altura da planta pela aplicação dos reguladores vegetais pode ser explicado pelo modo de ação dos produtos, que agem no metabolismo da síntese de giberelinas, hormônios que, entre outras funções, promovem o alongamento celular (Alvarez et al., 2007; Nascimento et al., 2009), o que, na prática, causa a drástica redução no alongamento celular (crescimento), sem causar deformação morfológica do caule (Nascimento et al., 2009; Alvarez et al., 2012). Além disso, esse resultado expressivo de redução da altura da planta pela aplicação dos inibidores vegetais foi decorrente, também, da época de aplicação do produto, que foi no momento da diferenciação do primórdio, atuando diretamente no estádio de alongamento do colmo (Alvarez et al., 2012).

O número de panículas $\mathrm{m}^{-2}$ foi significativamente afetado pela interação dos fatores. $\mathrm{O}$ aumento das doses proporcionou redução linear do número de panículas $\mathrm{m}^{-2}$, porém de forma mais acentuada com a aplicação do etiltrinexapac (Tabela 2 e Figura 2). Esses dados estão em consonância com os obtidos por Nascimento et al. (2009) que também observaram reduções gradativas dessa variável com o aumento das doses de ETX. Assim, pode-se inferir que os efeitos dos reguladores nas plantas relacionam-se com o ingrediente ativo utilizado, uma vez que Buzetti et al. (2006) não observaram diferenças no número de panículas $\mathrm{m}^{-2}$, quando se aplicou o cloreto de clormequat. Corroborando essas informações, Rajala \& Peltonen-Sainio (2001) relatam que o efeito do regulador de crescimento é dependente do tipo, do momento e da dose de aplicação.

O número de espiguetas panícula ${ }^{-1}$ foi influenciado apenas pelo fator doses ocorrendo redução linear com o aumento dessas (Tabela 2 e Figura 3). A fertilidade das espiguetas foi significativamente afetada pelos efeitos isolados dos fatores e pela interação entre eles. Com isso, verificaram-se reduções da fertilidade com o aumento das doses dos reguladores, com resultados mais nítidos no uso do ETX, que variou de cerca de $80 \%$, na dose zero, para $20 \%$, na maior dose (Tabela 2 e Figura 4). Esses resultados são semelhantes aos obtidos por Nascimento et al. (2009), que verificaram quedas significativas da fertilidade das espiguetas, com o aumento das doses de ETX. Segundo Alvarez et al. (2007), a redução da fertilidade das espiguetas pode ser resultado dos efeitos do regulador na formação de flores (estames e ovários) e na meiose. Portanto, os resultados permitem inferir que o regulador ETX foi mais prejudicial ao arroz, nessa característica, do que o paclobutrazol (PBZ) e o cloreto de mepiquat (CM). 
Tabela 1. Altura de plantas (ALT), número de panículas por metro quadrado (PAN), número de espiguetas por panículas (ESP), fertilidade das espiguetas (FERT), massa de 1000 grãos (M1000) e produtividade de grãos (PROD) do arroz de terras altas afetado pela aplicação de reguladores vegetais (etil-trinexapac, ETX; paclobutrazol, PBZ; e cloreto de mepiquat, CM)

\begin{tabular}{lcccccc}
\hline Regulador & ALT & PAN & ESP & FERT & M1000 & PROD \\
\hline & cm & unidade & unidade & $\%$ & gramas & kg ha $^{-1}$ \\
ETX & $79,06 \mathrm{~b}$ & $183 \mathrm{~b}$ & $105 \mathrm{a}$ & $52,59 \mathrm{~b}$ & $27,00 \mathrm{~b}$ & $2977 \mathrm{~b}$ \\
PBZ & $104,20 \mathrm{a}$ & $206 \mathrm{a}$ & $107 \mathrm{a}$ & $75,78 \mathrm{a}$ & $28,93 \mathrm{a}$ & $4618 \mathrm{a}$ \\
CM & $101,19 \mathrm{a}$ & $210 \mathrm{a}$ & $104 \mathrm{a}$ & $77,11 \mathrm{a}$ & $29,05 \mathrm{a}$ & $4467 \mathrm{a}$ \\
\hline C.V.(\%) & 8,10 & 9,94 & 8,02 & 4,16 & 10,60 & 21,57 \\
\hline
\end{tabular}

Médias seguidas de mesma letra, na coluna, não diferem pelo teste Tukey para $\mathrm{p}<0,05$.

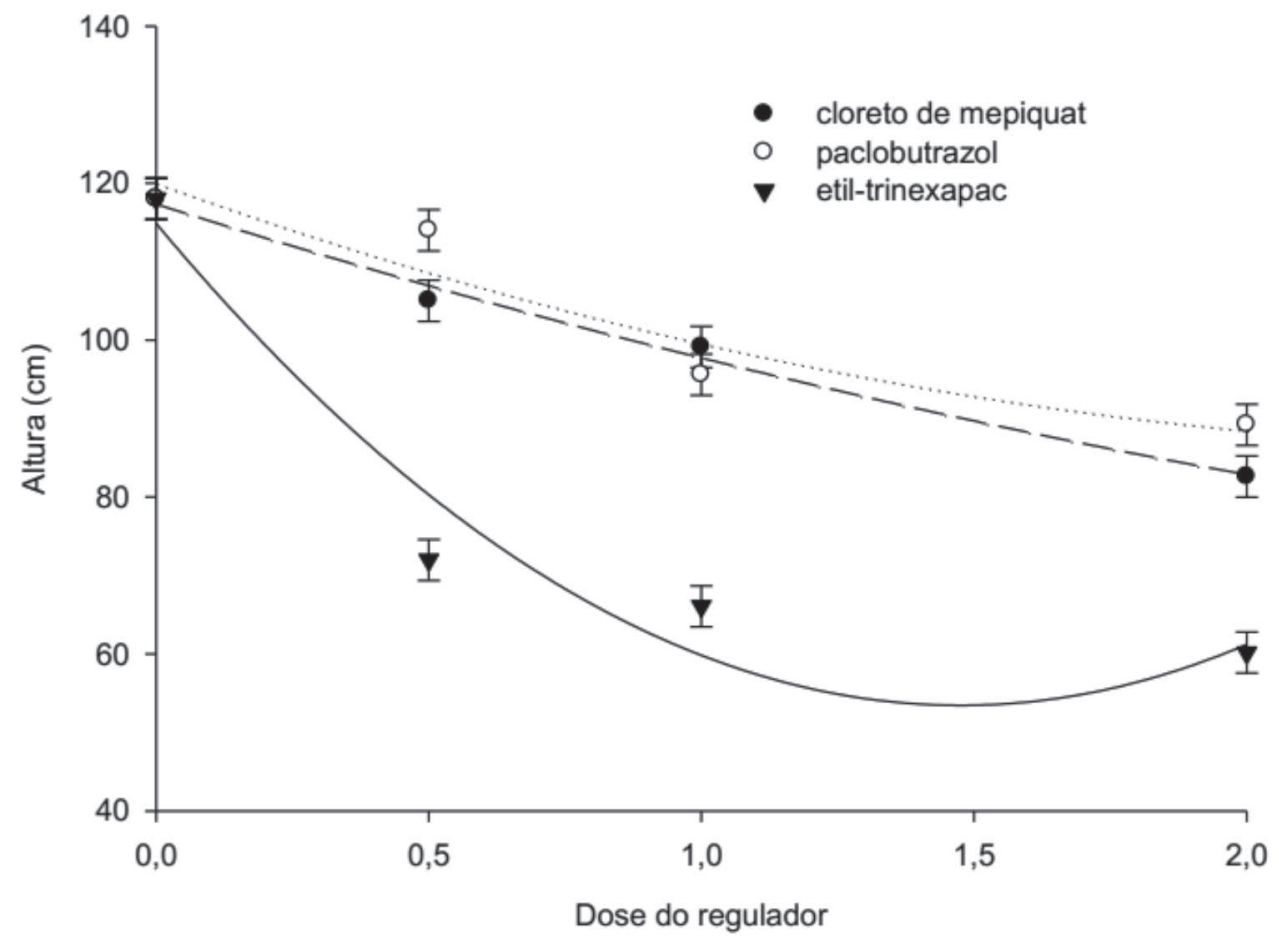

Figura 1. Altura de plantas de arroz em função de doses (0, 0,5, 1 e 2 vezes a dose recomendada) e fontes de reguladores vegetais (etiltrinexapax, paclobutrazol e cloreto de mepiquat). Barras verticais significam desvio padrão da média.

Tabela 2. Equações de regressão das variáveis altura de plantas, número de panículas $\mathrm{m}^{-2}$, número de espiguetas panículas ${ }^{-1}$, fertilidade das espiguetas, massa de 1000 grãos e produtividade de grãos de arroz em função de doses $(0,0,5,1$ e 2 vezes a dose recomendada) e fontes de reguladores vegetais (etil-trinexapax, ETX; paclobutrazol, PBZ e cloreto de mepiquat, CM)

\begin{tabular}{ll}
\hline Variável & \multicolumn{1}{c}{ Equações } \\
\hline Altura de plantas & ETX, $\hat{\mathrm{Y}}=114,9-83,2 \mathrm{x}+28,21 \mathrm{x}^{2}, \mathrm{R}^{2}=0,94 * *$ \\
& $\mathrm{CM}, \hat{\mathrm{Y}}=117,29-21,96 \mathrm{x}+2,37 \mathrm{x}^{2}, \mathrm{R}^{2}=0,99 * *$ \\
\hline Panículas $\mathrm{m}^{-2}$ & $\mathrm{PBZ}, \hat{\mathrm{Y}}=120,01-25,08 \mathrm{x}+4,67 \mathrm{x}^{2}, \mathrm{R}^{2}=0,92^{* *}$ \\
\hline Espiguetas / panícula & $\hat{\mathrm{Y}}=220,67-24 \mathrm{x}, \mathrm{R}^{2}=0,93 * *$ \\
\hline & $\hat{\mathrm{Y}}=116,4-12,36 \mathrm{x}, \mathrm{R}^{2}=0,99 * *$ \\
\hline Fertilidade das espiguetas & $\mathrm{ETX}, \hat{\mathrm{Y}}=81,94-33,54 \mathrm{x}, \mathrm{R}^{2}=0,96^{* *}$ \\
\hline Massa de 1000 grãos & $\mathrm{CM}, \hat{\mathrm{Y}}=79,26-2,46 \mathrm{x}, \mathrm{R}^{2}=0,90^{*}$ \\
\hline & $\mathrm{PBZ}, \hat{\mathrm{Y}}=79,57-4,35 \mathrm{x}, \mathrm{R}^{2}=0,99 * *$ \\
\hline Produtividade de grãos & $\hat{\mathrm{Y}}=30,53-2,51 \mathrm{x}, \mathrm{R}^{2}=0,97 * *$ \\
& $\mathrm{ETX}, \hat{\mathrm{Y}}=5873-5028 \mathrm{x}+1146 \mathrm{x}^{2}, \mathrm{R}^{2}=0,98^{* *}$ \\
\hline
\end{tabular}


A massa de 1000 grãos foi influenciada pela interação dos fatores. Ocorreu redução linear com a aplicação dos reguladores vegetais, porém, de forma mais acentuada com o uso do ETX (Tabela 2 e Figura 5). Machado et al. (1994) e Nascimento et al. (2009) relataram que condições externas adversas, durante a diferenciação e o desenvolvimento da panícula podem provocar degenera- ções, respectivamente, do primórdio ou da panícula jovem. Com isso, pode-se inferir que o uso dos reguladores em determinadas doses causou danos à panícula, com reflexos no número de espiguetas e na massa de 1000 grãos. Neste sentido, Buzetti et al. (2006), Alvarez et al. (2007), Nascimento et al. (2009) e Espíndula et al. (2011) acrescentam que o uso de reguladores pode in-

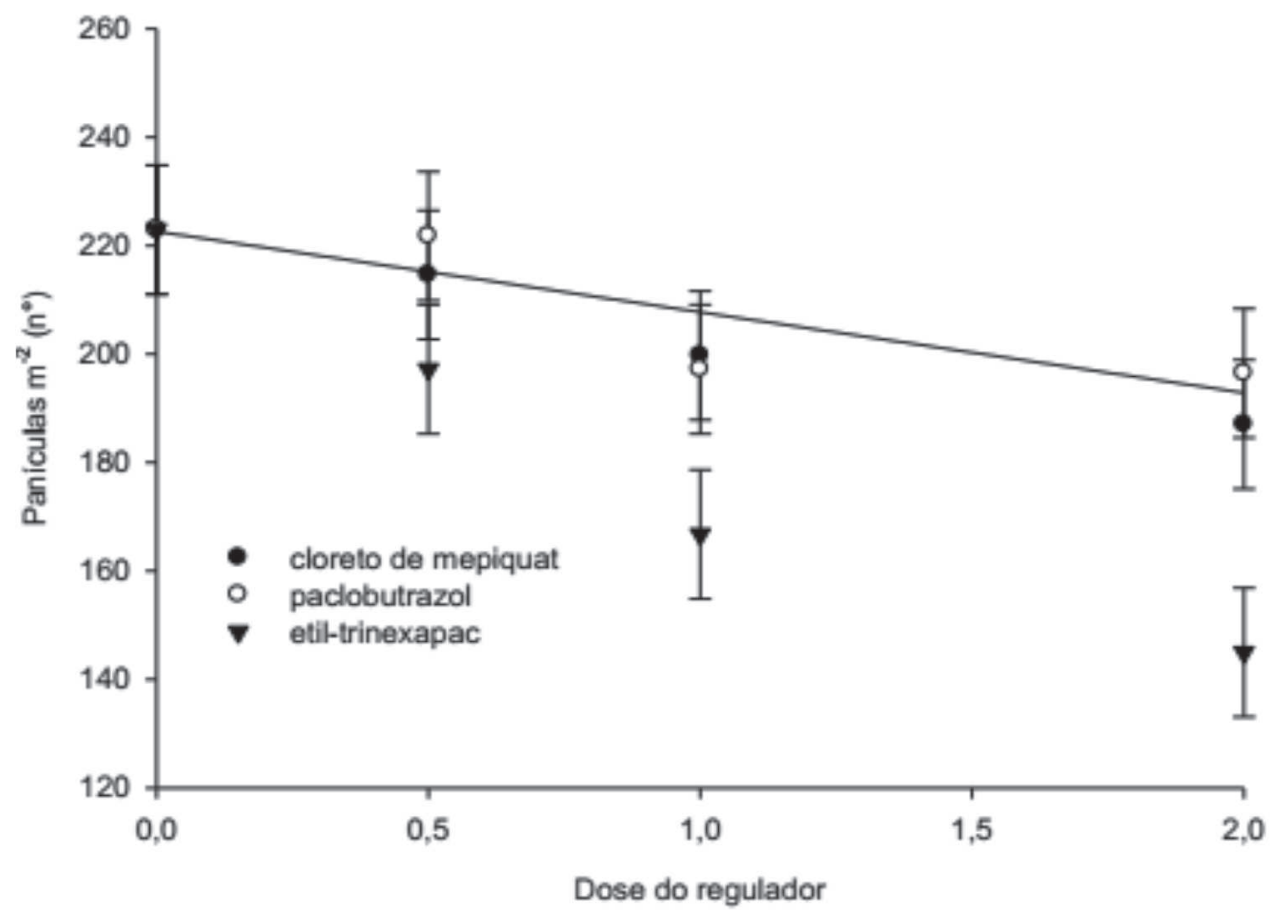

Figura 2. Número de panículas $\mathrm{m}^{-2}$ de plantas de arroz em função de doses $(0,0,5,1$ e 2 vezes a dose recomendada) e fontes de reguladores vegetais (etil-trinexapax, paclobutrazol e cloreto de mepiquat). Barras verticais significam desvio padrão da média.

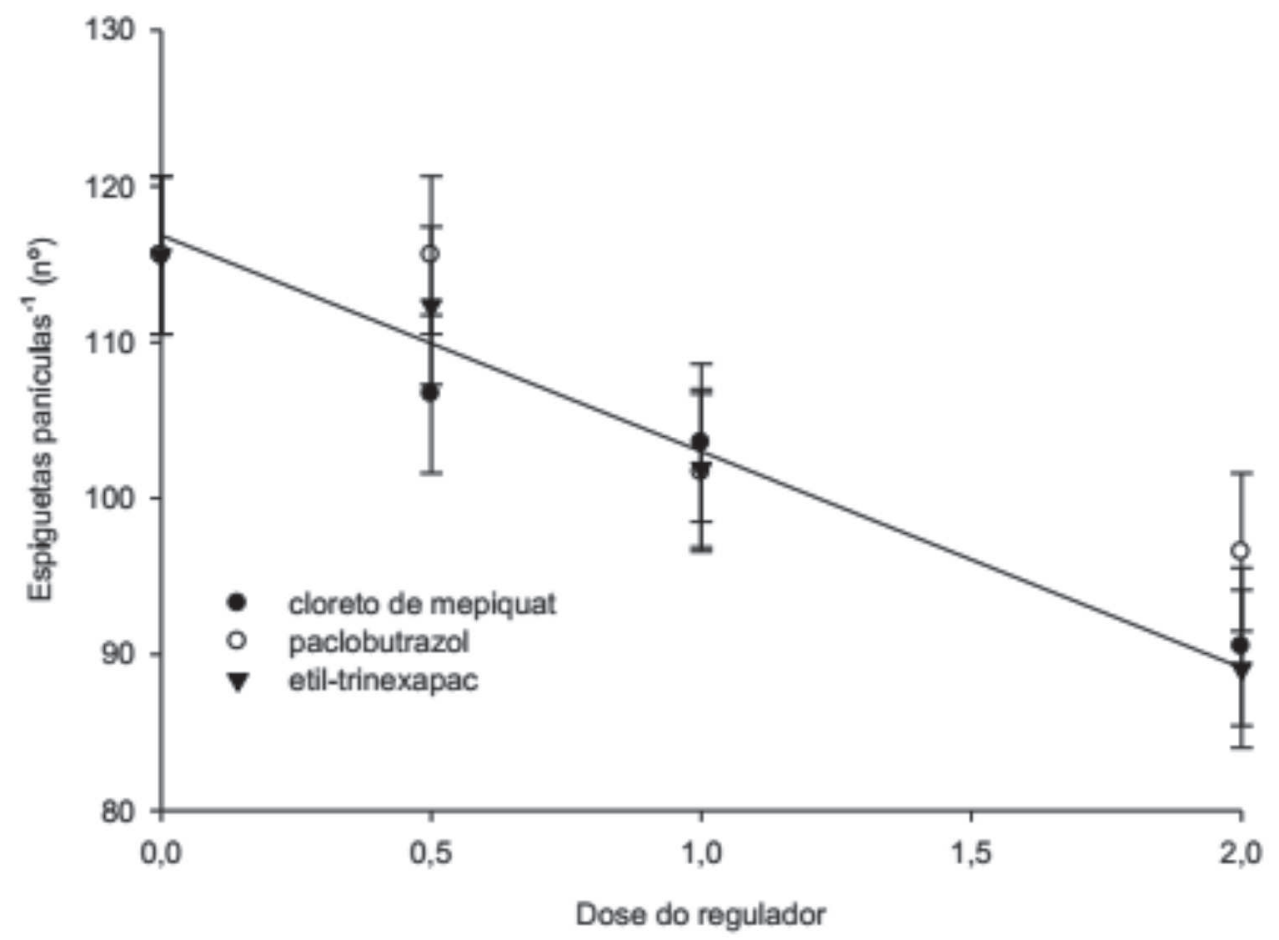

Figura 3. Número de espiguetas panículas ${ }^{-1}$ de plantas de arroz em função de doses ( $0,0,5,1$ e 2 vezes a dose recomendada) e fontes de reguladores vegetais (etil-trinexapax, paclobutrazol e cloreto de mepiquat). Barras verticais significam desvio padrão da média. 
fluenciar o desenvolvimento funcional da planta, sendo variável o efeito causado, nas culturas agrícolas, pelo princípio ativo.

Os efeitos dos reguladores nos componentes da produção refletiram-se diretamente na produtividade de grãos, ocorrendo efeito significativo da interação dose $\mathrm{x}$ regulador. Assim, constatou-se que a aplicação dos reguladores vegetais provocou redução da produtividade de grãos, à medida que as doses foram incrementadas (Tabela 2 e Figura 6), sendo o efeito mais intenso o verificado com a aplicação do ETX. Por outro lado, o CM e o PBZ causaram reduções menos expressivas, e, principalmente, nas menores doses, permitindo aliar redução da altura de plantas com produtividade superior a $5000 \mathrm{~kg} \mathrm{ha}^{-1}$.

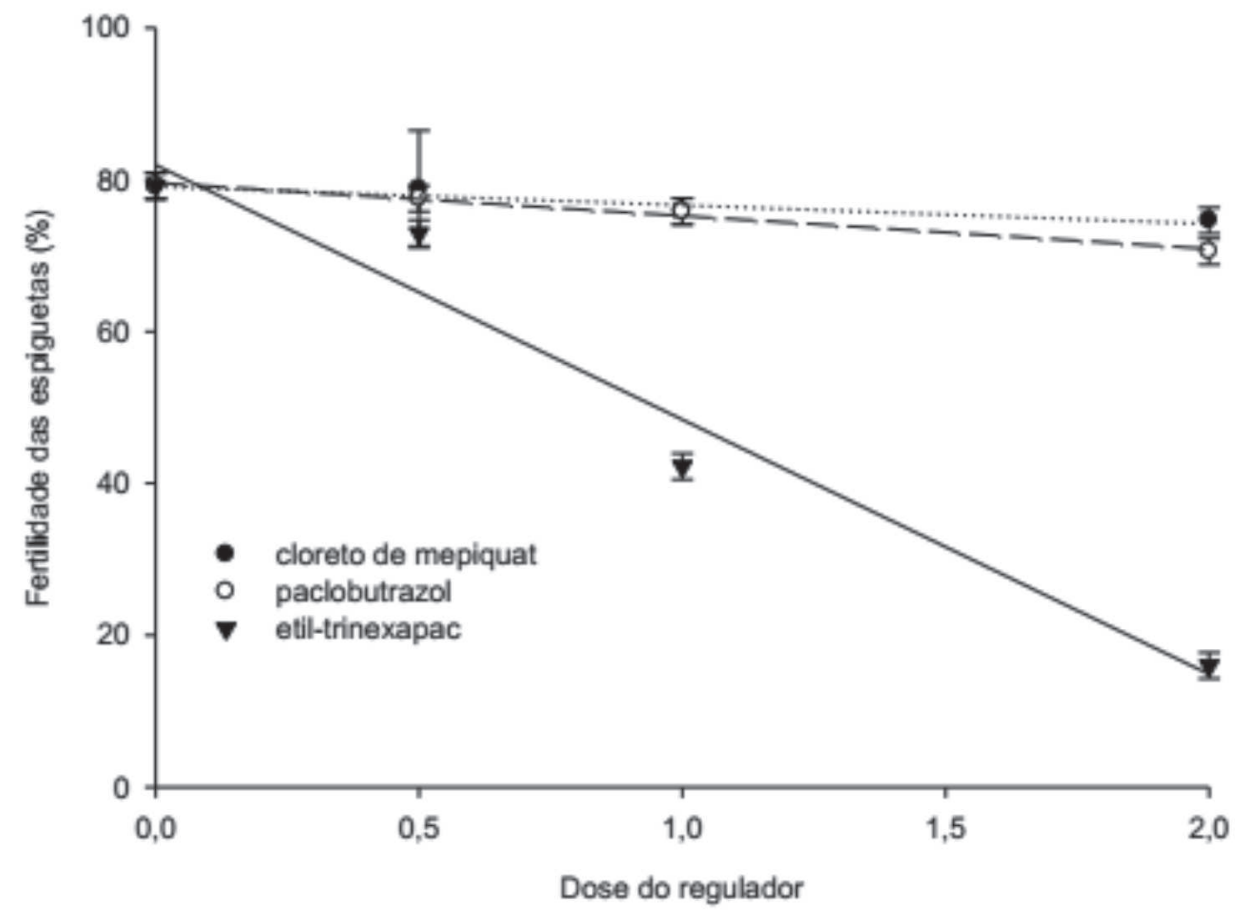

Figura 4. Fertilidade das espiguetas de plantas de arroz em função de doses (0, 0,5, 1 e 2 vezes a dose recomendada) e fontes de reguladores vegetais (etil-trinexapax, paclobutrazol e cloreto de mepiquat). Barras verticais significam desvio padrão da média.

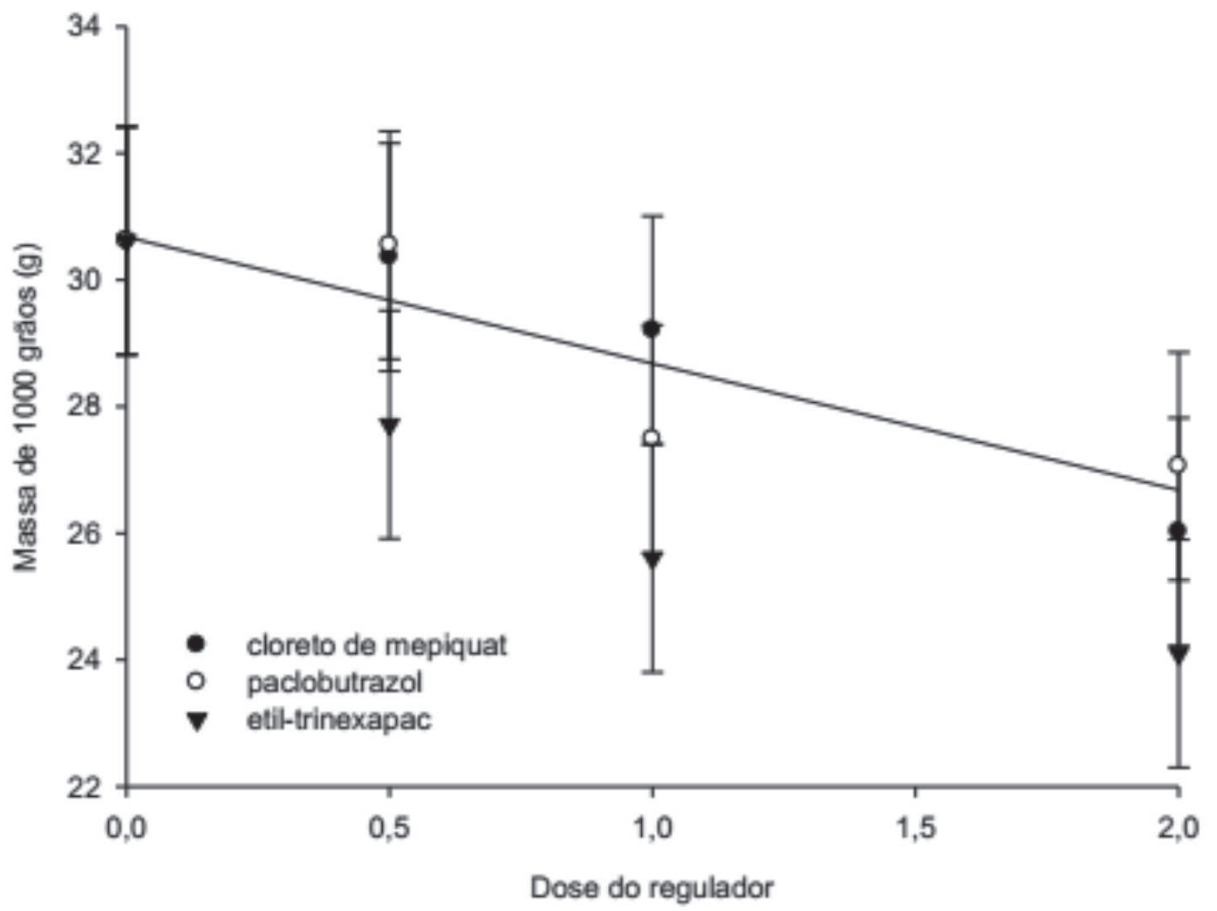

Figura 5. Massa de 1000 grãos de arroz em função de doses (0, 0,5, 1 e 2 vezes a dose recomendada) e fontes de reguladores vegetais (etil-trinexapax, paclobutrazol e cloreto de mepiquat). Barras verticais significam desvio padrão da média. 


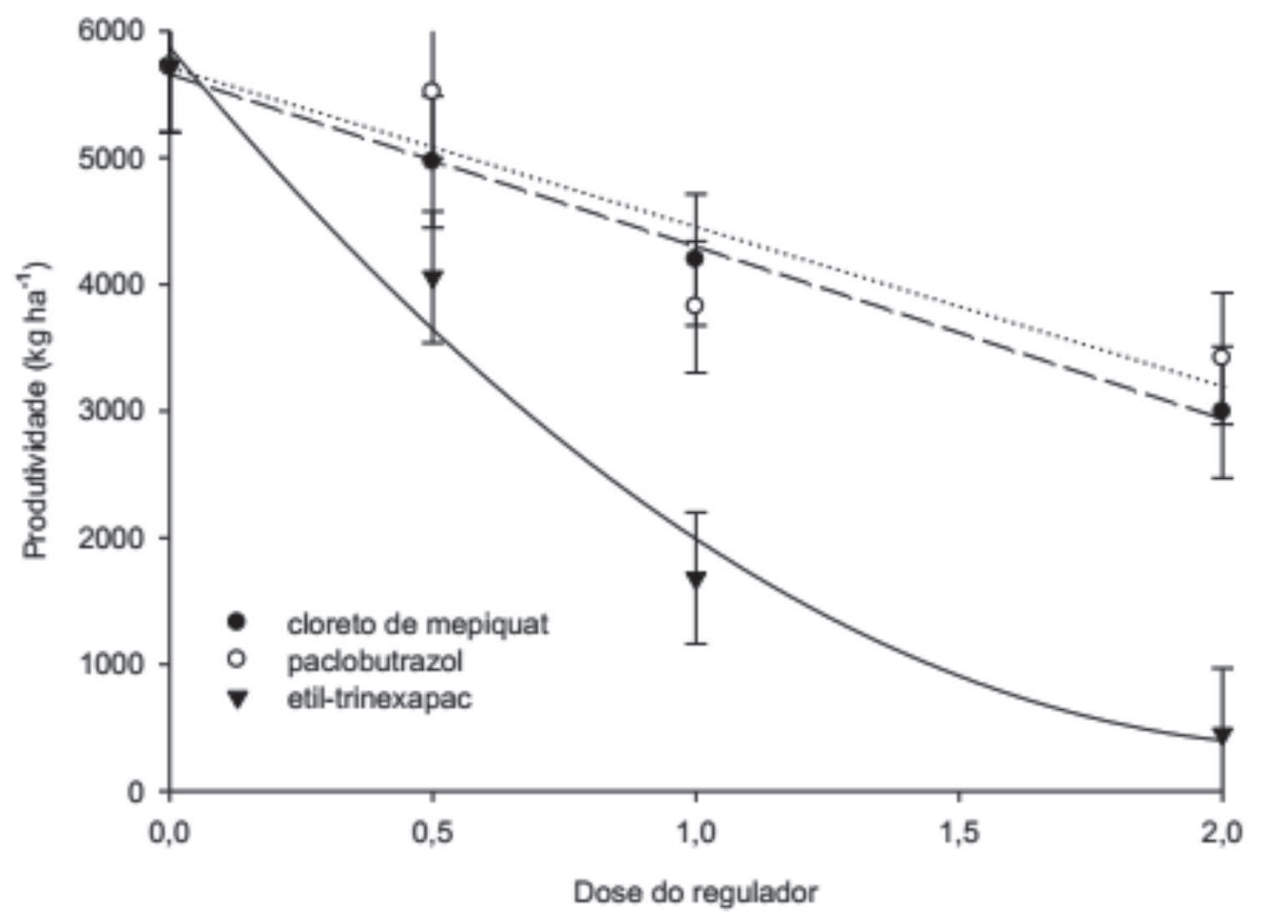

Figura 6. Produtividade de grãos do arroz em função de doses ( $0,0,5,1$ e 2 vezes a dose recomendada) e fontes de reguladores vegetais (etil-trinexapax, paclobutrazol e cloreto de mepiquat). Barras verticais significam desvio padrão da média.

Esses resultados discordam dos obtidos por Ilumae (2002), que, trabalhando com outras espécies vegetais, verificou que a aplicação de ETX reduziu a altura das plantas, sem comprometimento na produtividade da cevada de primavera (cv. Anni), do trigo de inverno (cv. Shirvinta) e do centeio de inverno (cv. Vambo). Entretanto, na cultura do arroz, também Alvarez et al. (2007) e Nascimento et al. (2009) observaram que a aplicação de ETX afetou a produtividade da cultura. Corroborando essas informações, Espíndula et al. (2011) relataram reduções da produtividade do trigo com o uso do ETX. Por outro lado, Buzetti et al. (2006) observaram que o uso do regulador de crescimento (cloreto de clormequat) não afetou a produtividade do arroz. Esses resultados permitem inferir que há necessidade de mais trabalhos de pesquisa, visando a identificar reguladores, doses e épocas de aplicação, para se obter a redução da altura de plantas sem afetar a produtividade de grãos. Segundo Nascimento et al. (2009), os efeitos dos reguladores de crescimento dependem de vários fatores, podendose destacar: temperatura, população de plantas, época de semeadura, cultivar, época de aplicação e doses utilizadas.

Adicionalmente, verifica-se que a produção de grãos de um dado cultivar de arroz é determinada por quatro componentes: 1) número de panículas por metro quadrado, 2) número de espiguetas por panícula, 3) fertilidade das espiguetas e 4) massa de 1000 grãos (Yoshida, 1981). Assim, com base nos resultados dos componentes da produção, a queda na produtividade de grãos ocorreu por causa de comprometimentos nesses componentes, notadamente na fertilidade das espiguetas, sendo mais pronunciada com o uso do ETX (Figuras 2 a 6). No entanto, vale ressaltar que este experimento tratou de assunto ainda novo, com relação à aplicação de reguladores vegetais na cultura do arroz de terras altas, irrigado por aspersão, visando a reduzir a altura da planta, e abre caminho para novas pesquisas, utilizando biorreguladores, e que PBZ e CM destacaram-se e proporcionaram maiores produtividades de grãos.

Sumarizando, verifica-se que a utilização dos reguladores vegetais proporcionou reduções significativas na altura de plantas do arroz de terras altas, o que pode ser excelente alternativa para produtores rurais que utilizam maior nível tecnológico na cultura, como a irrigação e a adubação nitrogenada, para evitar o acamamento de plantas. Por outro lado, todas as doses utilizadas provocaram reduções nos componentes de produção e, consequentemente, na produtividade de grãos da cultura, não tendo sido possível estabelecer a dose adequada, que aliasse a redução da altura das plantas com a capacidade de não acarretar diminuição da produtividade. Entretanto, verifica-se que a aplicação de metade ou da dose completa dos reguladores testados proporcionou redução da altura de plantas e menores quedas de produtividade. Dos reguladores utilizados, o ETX proporcionou a maior queda de produtividade, sendo, portanto, mais recomendada a utilização do PBZ ou a do CM. 


\section{CONCLUSÕES}

Os reguladores vegetais reduzem a altura da planta de arroz.

O aumento das doses dos reguladores reduziu os valores dos componentes de produção e produtividade de grãos do arroz.

O etil-trinexapac foi o regulador mais prejudicial à produtividade do arroz.

Não foi identificada a dose adequada de regulador que aliasse a redução da altura das plantas de arroz com a capacidade de não acarretar diminuição da produtividade de grãos.

\section{AGRADECIMENTOS}

À FAPESP pelo financiamento da pesquisa e ao CNPq pela concessão de bolsa ao segundo autor.

\section{REFERÊNCIAS}

Alvarez RCF, Crusciol CAC, Rodrigues JD \& Alvarez ACC (2007) Aplicação de reguladores vegetais na cultura de arroz de terras altas. Acta Scientiarum. Agronomy, 29:241-249.

Alvarez RCF, Crusciol CAC, Nascente AS, Rodrigues JD \& Habermann G (2012) Gas exchange rates, plant height, yield components, and productivity of upland rice as affected by plant regulators. Pesquisa Agropecuária Brasileira 47:1455-1461.

Bosco LC, Grimm EL \& Streck NA (2009) Crescimento e desenvolvimento de genótipos de arroz cultivados em solo alagado e não-alagado. Revista Ceres, 56:796-804.

Buzetti S, Bazanini GC, Freitas JG, Andreotti M, Arf O, Sá ME \& Meira FA (2006) Resposta de cultivares de arroz a doses de nitrogênio e do regulador de crescimento cloreto de clormequat. Pesquisa Agropecuária Brasileira, 41:1731-1737.

Campos MF, Ono EO \& Rodrigues JD (2009) Desenvolvimento da parte aérea de plantas de soja em função de reguladores vegetais. Revista Ceres, 56:74-79.

Crusciol CAC, Toledo MZ, Arf O \& Cavariani C (2012) Water supplied by sprinkler irrigation system for upland rice seed production. Bioscience Journal, 28:34-42.

CONAB - Companhia Nacional de Abastecimento (2011) $4^{\text {o }}$ Levantamento da produção de grãos - safra 2010/11. Disponível em: <www.conab.gov.br>. Acessado em: 05 de dezembro de 2011.

Embrapa - Empresa Brasileira de Pesquisa Agropecuária (1999) Sistema Brasileiro de Classificação de Solos. Rio de Janeiro, Embrapa/CNPSO. 412p.

Espíndula MC, Rocha VS, Souza LT, Souza MA, Campanharo M \& Grossi JAS (2011) Rates of nitrogen and growth retardant trinexapac-ethyl on wheat. Ciência Rural, 41:2045-2052.

Fageria NK, Moreira A \& Coelho AM (2011) Yield and yield components of upland rice as influenced by nitrogen sources. Journal of Plant Nutrition, 34:361-370.

Fialho CMT, Ferreira EA, Meira RAS, Santos JB, Silva AA, Freitas FCL, Galon L, Concenço G, Silva AF, Tironi SP \& Rocha PRR (2009) Caracteres morfoanatômicos de Brachiaria brizantha submetida à aplicação de Trinexapac-Ethyl. Planta daninha, 27:533-539.
Ilumae E (2002) The influence of growth regulator Moddus 250 EC on different cereal species. Journal of Agricultural Science, 13:73-78.

Machado EC, Lagoa AMMA, Ticelli M, Azzini LE \& Tisselli F (1994) Fotossíntese e crescimento de panículas em arroz de sequeiro (Oryza sativa L. cv. IAC 165). Revista Brasileira de Botânica, 17:37-43.

Nascimento V, Arf O, Silva MG, Binotti FFS, Rodrigues RAF \& Alvarez RCF (2009) Uso do regulador de crescimento etiltrinexapac em arroz de terras altas. Bragantia, 68:921-929.

Rademacher W (2000) Growth retardants: effects on gibberellin biosynthesis and other metabolic pathways. Annual Review Plant Physiology of Plant Molecular Biology, 51:501-531.

Raij B van, Cantarella H, Quaggio JA \& Furlani AMC (1996) Recomendações de adubação e calagem para o Estado de São Paulo. $2^{\mathrm{a}}$ ed. Campinas, Instituto Agronômico e Fundação IAC. 285p. (Boletim técnico, 100).

Rajala A \& Peltonen-Sainio P (2001) Plant growth regulator effects on spring cereal root and shoot growth. Agronomy Journal, 93:936-943.

Rodrigues RAF, Soratto RP \& Arf O (2004) Manejo de água em arroz de terras altas no sistema de plantio direto, usando o tanque classe A. Engenharia Agrícola, 24:546-556.

Soares AA, Cornélio VMO, Soares PC, Santos PG \& Reis MS (2001) Primavera: cultivar de arroz com grãos agulhinha para cultivo em terras altas. Revista Ceres, 48:381-388.

Soares AA, Cornélio VMO, Reis MS, Soares PC, Santos PG \& Sousa MA (2003) Desempenho de linhagens de arroz de terras altas quanto à produtividade de grãos e outras características em Minas Gerais. Revista Ceres, 50:509-525.

Viana RS, Silva PH, Mutton MA, Mutton MJR, Guimarães ER \& Bento M (2008) Efeito da aplicação de maturadores químicos na cultura da cana de açúcar. Acta Scientiarum. Agronomy, 30:6571 .

Zagonel J \& Fernandes EC (2007) Doses e épocas de aplicação de redutor de crescimento afetando cultivares de trigo em duas doses de nitrogênio. Planta daninha, 25:331-339.

Yoshida S (1981) Fundamentals of Rice Crop Science. Laguna, Los Baños. 269p. 